\title{
SISTEMA REGIONAL DE INOVAÇÃO E DESENVOLVIMENTO
}

\author{
Silvio A. F. Cario* \\ Daniela C. Lemos** \\ Pablo F. Bittencourt***
}

\section{Introdução}

Inovação é um processo social, aberto e dinâmico em que agentes interagem num determinado ambiente institucionalmente constituído, com propósito de promover mudança técnica. Para tanto, a construção de ambiente institucional ativo em um país que possibilite o desenvolvimento inovativo, constitui um requerimento básico. Autores neoschumpeterianos vem, nos últimos tempos, dando diferentes ênfases analíticas nos estudos sobre sistema de inovação para além do escopo nacional. Apontam que os espaços regional e local constituem, cada vez mais, importante marco de estudo. Nestas dimensões espaciais encontram-se condições para compreensão mais realistas do sistema de inovação de um país, uma vez que focar o sistema inovativo em determinado espaço territorial, permite refinar a análise dado que valores, hábitos, cultura e outros aspectos comportamentais dos agentes somam-se com processos históricos de formação econômica, especificidades da infraestrutura tecnológica; conteúdo das políticas de inovação para determinada área geográfica, entre outros aspectos.

Em reforço a este argumento, Niosi (2002) aponta que o conceito de Sistema Nacional de Inovação (SNI) tem se expandido através dos sistemas de inovação para outras dimensões, seja local ou regional ou ainda em termos setoriais, congregando campos de tecnologia em comum. Na mesma linha de consideração, Edquist (1997) aponta que as diferentes ênfases nos sistemas de inovação - nacional, regional, local e setorial - são úteis, dado que tais perspectivas possuem semelhanças que permitem agrupá-las como variantes de uma abordagem mais abrangente dos sistemas de inovação.

Lundvall et al (2002) acrescentam que outros níveis de análise além do nacional são necessários para se obter uma compreensão mais realista do funcionamento dos

\footnotetext{
*Professor do Departamento de Economia e Relações Internacionais da Universidade Federal de Santa Catarina (UFSC). E-mail: fecario@yahoo.com.br

**Professora do Departamento de Administração da Universidade Estadual de Santa Catarina (UDESC). E-mail: lemosda@gmail.com

***Professor do Departamento de Economia e Relações Internacionais da Universidade Federal de Santa Catarina (UFSC). E-mail: pablofelipe.bittencourt@gmail.com
} 
sistemas nacionais, nas restrições e eficácia das políticas adotadas. O estabelecimento de políticas regionais também exige foco nos sistemas regionais e compreensão da evolução dos sistemas setoriais. Além disso, é difícil em muitos casos generalizar os efeitos da política nacional para especificar um sistema de inovação genérico, sem considerar as particularidades regionais (COOKE; URANGA; ETXEBARRIAl, 1997).

Neste contexto, este trabalho procura apontar aspectos relacionados ao sistema de inovação sob perspectiva regional, considerando que estudos sobre processo inovativos em espaço geograficamente delimitado, permitem ter uma melhor compreensão das especificidades que impulsionam e dificultam os processos inovativos. Para tanto, encontra-se dividido em 4 seções, sendo que nesta $1^{\text {a }}$. seção traça-se seu objetivo; na $2^{\text {a }}$. seção apresentam-se conceitos elaborados por diferentes autores sobre sistema nacional de inovação, bem como atores participantes e algumas abordagens em pauta; na $3^{\mathrm{a}}$. seção apresentam-se os conceitos, componentes e taxonomias de um sistema regional de inovação; e, na 4 a . seção, destacam-se elementos característicos de um sistema ino vativo com base regional; e por fim, na $5^{\mathrm{a}}$. seção, realça a visão de que um sistema inovativa cria melhores condições para o exercício da atuação no Estado, na formulação de políticas voltadas à promoção do desenvolvimento inovativo.

1. Sistema de Inovação: significado, participantes e abordagens

Freeman (1995); Lundvall et al (2002; 2009); Freeman; Soete (2008) creditam a Friedrich List e a sua obra "The national system of political economy”, publicado em 1841, as ideias seminais que geraram a abordagem dos SNIs argumentando que o autor, apesar de não utilizar tal terminologia, antecipou muitos aspectos dos debates contemporâneos sobre este tema. Neste sentido, destacam que List chamava atenção para a importância do capital intelectual e da vinculação da produção às instituições formais de ciência e de ensino; reconhecia a interdependência da importação de tecnologias estrangeiras com o desenvolvimento técnico local; além de dar ênfase ao papel do Estado na coordenação e execução de políticas para o desenvolvimento da indústria e da economia.

Em tempo mais recente, Lundvall (1992) destaca que List reforçava a responsabilidade governamental com relação à educação e formação de pessoal bem como a criação de uma infraestrutura de apoio ao desenvolvimento industrial. Assim, List foi uma força de inspiração vital para a pesquisa corrente em SNI (ELAN, 1997). Nesta 
perspectiva analítica, Freeman (1987) foi o primeiro a utilizar a expressão "Sistema Nacional de Inovação" em sua obra intitulada “Technology Policy and Economic Performance: Lessons from Japan” (LUNDVALL, 1992; 2007; EDQUIST, 1997; 2007). Nesta, discutiu sobre as habilidades das diferentes nações em explorar o processo de inovação e difusão de tecnologia em seu próprio benefício e quais políticas poderiam contribuir a este respeito. Utiliza, para tanto, o termo SNI para congregar os fatores que dentro de cada nação poderiam ser utilizados para explicar estas diferenças nos processos inovativos (FAGERBERG; SAPPRASERT, 2011).

Igualmente citadas como referência dentro desta abordagem são as obras de Lundvall (1992) "National Systems of Innovation: toward a theory of innovation and interactive learning”, e Nelson (1993) “National Innovation Systems: a comparative analysis”, sendo que a primeira faz uma discussão teórica acerca do SNI, ressaltando entre outros aspectos a importância do aprendizado e da interação no processo de inovação e a segunda, de natureza mais empírica, apresenta estudos de casos de SNIs de 15 diferentes países, traçando um comparativo entre as diferentes realidades nacionais (EDQUIST, 1997; 2007).

Desta forma verifica-se que a literatura sobre SNI começa a emergir a partir da segunda metade da década de 80, com importantes contribuições no início dos anos 90 que crescem gradativamente nos anos 2000 (LUNDVALL et al, 2009). Utilizando evidências bibliométricas, Fagerberg; Sapprasert, (2011) sustentam que a literatura sobre SNI vem colaborando para a integração das políticas científica, tecnológica, de pesquisa e de inovação, que normalmente caminham separadas, contribuindo para o desempenho de países e regiões.

Para Niosi (et al, 1993) um SNI constitui um o sistema de interação das empresas privadas e públicas, universidades e agências governamentais no propósito de criar condições para o desenvolvimento da ciência e tecnologia dentro da fronteira territorial de um país. Antes, Lundvall (1992, p. 89) apontara que um SNI expressa: “Os elementos e relacionamentos que interagem na produção, difusão e utilização de conhecimentos novos e economicamente úteis e estão localizados dentro ou enraizados nas fronteiras de um Estado-nação”.

Lundvall (1992) assume que as economias nacionais diferem quanto à estrutura do sistema de produção e quanto ao quadro institucional, que aliadas a questões como experiência, língua e cultura geram especificidades nacionais na organização interna das empresas, nos relacionamentos inter-empresas, no papel do setor público, na atuação do 
sistema financeiro na promoção das inovações e na intensidade e organização das atividades de $\mathrm{P} \& \mathrm{D}$.

Neste sentido, um sistema de inovação pode ser constituído como uma rede de instituições dos setores público e privado, cujas atividades voltam-se para interação, criação, alteração, importação e difusão de novas tecnologias. Figuram nesta rede: universidades, institutos de pesquisa e centros de pesquisa e desenvolvimento (P\&D) agências governamentais de fomento e financiamento; empresas públicas e privadas, associações empresariais, organizações não-governamentais, usuários e clientes no mercado, dentre outros, conforme sinaliza a Figura 1. Enfim, um sistema inovativo constitui-se de um conjunto de atores que se voltam para a capacitação técnica, que estimula a inovação em seu sentido amplo - produto, processo, organizacional, etc. - com o objetivo de conduzir a economia para o crescimento.

Figura 1: Composição do sistema de inovação

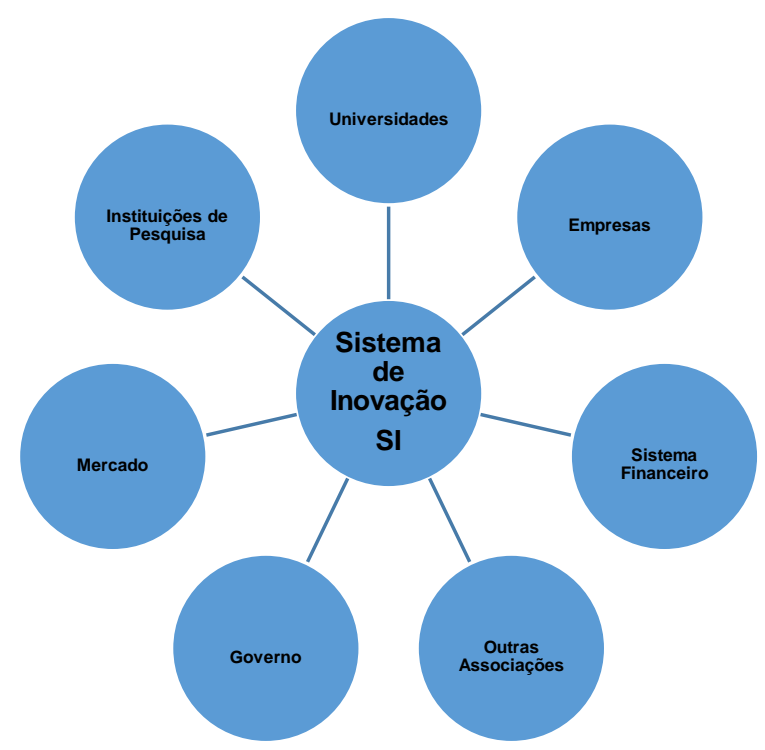

Fonte: Elaboração própria.

Os atores que compõem o SNI bem como as relações que se formam em seu interior dependem das características de cada país, tais como o tamanho e grau de desenvolvimento, além do papel específico dos principais protagonistas no processo de inovação (empresas, organismos de pesquisa públicos e privados e outras instituições públicas) e as formas, qualidade e intensidade de suas interações, conforme demonstra a figura 2. Desta forma, tais atores sofrem a influência de vários fatores que são próprios 
do país, tais como: sistema financeiro e governamental das empresas, marcos jurídicos e regulatórios, nível de instrução e qualificação, grau de mobilidade da mão-de-obra, relações de trabalho, práticas de gestão em vigor e outros. O papel do poder público se reflete de certo modo na estrutura de financiamento público em P\&D (OCDE, 1999).

Os estudos sobre sistema de inovação foram incorporando ao longo do tempo, novos escopos analíticos de base neo-schumpeteriana. Contudo, um marco importante e distinto em termos de perspectiva analítica, encontra nos estudos realizados no início dos anos 90, considerados de abrangência restrita tratada por Nelson (1993) e de visão ampla de Lundvall (2002). Enquanto, nos últimos tempos, novos elementos analíticos tem sido suscitados como o de incorporar mais teoria no âmbito do conceito, no propósito de proporcionar maior sustentação analítica, como observa o Edquist (2005). Assim como, outros requerimentos expressos por Lundvall et all (2014) e Pietrobelli e Rabelotti (2009e 2011) acerca da necessidade de analisar os sistema inovativos sob o ângulo da atual organização industrial, posta sob a forma de cadeia global de valor.

O estudo comparativo sobre sistema de inovação realizado por Nelson (1993) foi considerado sob perspectiva restrita dos determinantes da inovação. Tal consideração decorre dos resultados apontarem que os processos inovativos provém da relação entre a estrutura de ciência e tecnologia (C\&T), políticas adotadas e o desempenho inovador das empresas existentes em cada país. Tal conclusão sustentou-se pela maior atenção e apoio que a infraestrutura tecnológica promovedora das atividades de $P \& D$ tradicionalmente recebe. Tal atenção e recursos sustentam funções que possibilitam o exercício de melhores condições para promoção e difusão do conhecimento e, por consequência promover inovações (Nelson e Rosemberg, 1993).

Lundvall (2002), por sua vez, aponta, a partir das experiências dos sistemas inovativos dos países nórdicos, que o sucesso alcançado na estrutura industrial, capacidade inovativa e sustentação da competitividade, decorre de mecanismos de aprendizagem não-intensivos em conhecimentos científicos. As interações entre produtores-fornecedores-usuários geram capacidade inovativa de longo alcance, estabelecida a partir de diferentes formas de aprendizado. Nesta perspectiva, a capacidade inovativa decorre além das estruturas internas formais de aprendizagem, como learning by searching. Outras manifestações encontram-se presentes, dentre as quais learning-byusing e learning-by-interacting. Para tanto, requerimentos como cultura, valores, comportamento, lealdade, confiança e poder enraizados em cada espaço nacional, contribuem para o firmamento de relações interativas dinâmicas pró-inovação. 
Um requerimento importante que tem sido colocado no meio acadêmico nos últimos tempos refere-se à necessidade de dar maior sustentação teórica ao conceito de sistema de inovação, uma vez que seu uso de forma intensa tem fragilizado seu approach. Neste contexto, Edquist (2007) defende a ideia de que os estudos passem a dedicar mais atenção à construção teórica, pois fortaleceria as análises sobre estudos de caso, em geral. Em outras palavras, tornaria a estrutura mais consistente, a partir de definição conceitual de seus componentes, relações, funções e a extensão. Esta preocupação é reforçada por Lundvall (2002 e 2007), mas com ressalva, dado que problemas que podem ocorrer em se firmar relações causais definitivas - como ocorre nas ciências naturais -, em campo das ciências sociais. Em complemento, aponta que uma teoria sobre sistema de inovação deve levar em consideração as dimensões geográficas e históricas.

Uma abordagem que vem crescendo ultimamente sobre sistema de inovação, refere-se incorporação da nova forma de organização industrial, expressa pelas cadeias globais de valor, no marco da estrutura institucional promovedora de inovação. Segundo Lundvall, et.all (2014), um requerimento importante é compreender o ingresso e a atuação de empresas localizadas em países em desenvolvimento em cadeias globais de valor, e seu papel ativo ou passivo no processo inovativo. Realça a importância de se verificar como se criam condições internas nos países para que suas empresas possam desenvolver upgradings de processo, de produto e de funcionalidade, como apontara antes, Humphrey e Schmitz (2000). Para tanto, os estudos desenvolvidos vêm salientando a importância de analisar as estruturas de governança, e dentro destas verificar como os fluxos de conhecimento transitam e são transferidos, bem como os mecanismos de aprendizados geram condições de promoção de mudança técnica no âmbito das redes estabelecidas (PIETROBELLI; RABELOTTI, 2009 e 2011).

De uma forma geral, segundo Edquist (2007) a abordagem dos sistemas de inovação vem se difundido, rapidamente, tanto no meio acadêmico como entre os responsáveis pela elaboração de políticas públicas. Neste sentido, destaca os principais requerimentos: (1) trazer como foco da discussão os processos de aprendizado e inovação; (2) adotar uma perspectiva holística e interdisciplinar; (3) empregar a perspectiva histórica e evolucionária; (4) enfatizar a interdependência e a não linearidade; (5) abranger tanto inovação em produtos quanto em processos, bem como as subcategorias destes tipos de inovação; (6) dar ênfase no papel das instituições. 
2. Sistema Regional de Inovação: significado, componentes e taxonomias

O conceito de Sistema Regional de Inovação (SRI) data dos anos 90, seguindo as obras clássicas de Freeman (1987), Lundvall (1992) e Nelson (1993). “Como a cronologia sugere, o conceito de SRI foi inspirado no conceito de SNI e baseia-se em raciocínio semelhante ao que enfatiza os sistemas de inovação de base territorial” (ASHEIN; GERTLER, 2007, p.299). Os autores ainda acrescentam que a emergência do conceito coincide com o sucesso dos clusters regionais e distritos industriais da era pós-fordista.

Doloreux (2002) comenta que é difícil verificar uma distinção precisa entre os conceitos de SNI e SRI, uma vez que alguns autores categorizam as ideias em diferentes conceitos e outros consideram os sistemas regionais como subconjuntos dos sistemas nacionais. Um elemento importante de distinção é, dentro de uma abordagem descritiva e normativa, capturar como o desenvolvimento inovativo ocorre dentro de um território. Neste sentido, as características institucionais - cultura, comportamento, tradição, valores, normas, leis, estatutos - da região, infraestrutura e sistemas de transferência de conhecimento e as estratégias e desempenho das empresas representam condições básicas e estímulos para promover atividades de inovação. (DOLOREUX; PARTO, 2005, p.148).

Considerando esta referência básica, os estudos buscam compreender a existência de um específico sistema de inovação em uma região, a partir de características locais, diferentes, ainda que integrante, de um sistema inovativo, cuja fronteira é nacional. Assim sendo, distintos significado de SRI são explicitados por autores que estudam sistemas inovativos:

a) Ashein; Coenen, (2005, p. 1177) definem SRI a partir da existência de “(...) infraestrutura institucional de apoio à inovação, dentro da estrutura de produção de uma região";

b) Wolf (s/d, p. 8 apud: Nauwelaers; Reid (1995) tratam o SRI como um “(...) conjunto de relações econômicas, políticas e institucionais que ocorrem em uma determinada área geográfica, gerando um processo de aprendizado coletivo com rápida difusão do conhecimento e melhores práticas”;

c) Cooke et all (1998, p.1581) conceituam SRI como “(...) um sistema em que empresas e outras organizações estão sistematicamente envolvidas na aprendizagem interativa, através de um ambiente institucional regional enraizado"; e,

d) Doloreux (2002, p. 249) conceitua SRI como um arranjo composto de que “(...) um conjunto de atores públicos e privados que estabelece, de forma sistemática, um 
padrão de interação capaz de aumentar e melhorar as capacidades de aprendizado localizadas em uma região".

A região constitui, a partir deste conjunto de definições, o locus dos processos inovativos. Critérios, portanto, são eleitos para se definir a abrangência de um determinado espaço geográfico em que são criadas as condições para o desenvolvimento inovativo. Cook et all (1998) aponta quatro critérios que definem uma região: $1^{\circ}$.) não deve ter um limite de tamanho determinado; $2^{\circ}$.) apresentar homogeneidade e identidade em relação a certos critérios específicos; $3^{\circ}$.) distinguir a área limítrofe por um tipo particular de recurso selecionado; e, $4^{\circ}$.) possuir algum tipo de coesão social interna. Em contribuição mais recente, Cook (2002) agrega outro elemento classificatório: 5º.) critérios devem ser estabelecidos dentro de um determinado período. Com estes critérios, tem-se um determinado espaço territorial geográfico menor que o Estado nacional, dotado de elementos característicos distintos, que criam condições para o desenvolvimento de sistemas inovativos regionais.

Os principais componentes de SRI são os mesmos que integram um SNI, destaque para as empresas, as instituições, a infraestrutura de conhecimento (estruturas de suporte à inovação que promovam a difusão da tecnologia; agências de transferência de tecnologia e conhecimento e instituições de $P \& D$, como universidades, institutos de pesquisa e laboratórios de pesquisa) e as políticas orientadas para inovação, com foco e ações vinculadas ao desenvolvimento regional. Ressalta-se que tais componentes, situados no espaço regional, não só interagem e cooperam entre si, como também realizam tais ações com outras estruturas situadas em espaço além da configuração regional, como as que se encontram nos níveis: mesoregional, estadual, nacional e internacional.

Um SRI pode ser avaliado sob dupla perspectiva: (1) a abordagem de regionalização que relaciona a região à sua competência (jurisdição), valorizando o grau de autonomia para desenvolver políticas e gerenciar os diferentes elementos que compõem o sistema regional e ainda a capacidade de financiamento para investimentos em infraestrutura necessária ao processo inovativo; (2) a abordagem do regionalismo, relacionada com a base cultural da região que lhe confere certo nível de potencial sistêmico capaz de estabelecer uma nova ordem institucional, criando novas normas, rotinas e hábitos e uma nova estrutura de governança (COOKE; URANGA; ETXEBARRIA, 1997). A regionalização envolve a constituição de arranjos no propósito de estimular o desenvolvimento de instituições regionais; enquanto (...) o regionalismo 
envolve a concepção de organizações regionais para dar expressão ativa para instituições regionais”. (COOKE; URANGA; ETXEBARRIA 1998, p.1574). Tal distinção, segundo os autores, permite entender porque algumas regiões economicamente menos favorecidas podem mostrar uma melhor capacidade de inovação, mobilizando seu capital social.

Por sua vez, esforços têm sido realizados por muitos grupos de pesquisa em vários países no propósito de criar tipologias de sistemas regionais de inovação. Com base em estudos anteriores Ashein; Gertler (2007, p.300-303) definem três tipos de SRI: (1) sistema de inovação territorialmente integrado - as empresas firmam atividades inovativas em processos de aprendizado localizados, estimulados pela proximidade geográfica, social e cultural, sem muita interação direta com organizações de conhecimento”. São exemplos, as redes de pequenas empresas dos distritos industriais, como é o caso da região italiana de Emilia-Romagna; (2) sistema de inovação regional em rede - (...) empresas e organizações incorporadas em uma região específica caracterizada pelo aprendizado interativo localizado". Neste, existe uma infraestrutura institucional de suporte à inovação, como acontece na Alemanha, Áustria e nos países nórdicos; e (3) sistema de inovação nacional regionalizado - caracteriza-se pela importância dos relacionamentos com atores exógenos (universidades, institutos de pesquisa, outras corporações) e pela cooperação entre pessoas de mesmo nível educacional ou ocupacional. Os parques científicos são exemplo deste último tipo.

Outro padrão de classificação é encontrado no estudo de Doloroux (2002), cujo resultado aponta existência de: $1^{0}$.) regiões com forte, médio e fraco potenciais para desenvolverem sistema de inovação; $2^{\circ}$.) nível de integração ao sistema nacional de inovação ou sistema único e próprio de inovação; $3^{\circ}$.) existência ou não de coesão social na região em favor da inovação; $4^{\circ}$.) modos de governança e formas de transferência de tecnologia; e, $5^{\circ}$.) barreiras regionais e obstáculos a inovação.

Numa análise mais ampla, Doloroux (2002) criou uma taxonomia com base em pesquisas e estudos que assinalam diferenças significativas entre os diversos SRIs, sugerindo um agrupamento em cinco tipos, que por sua vez se dividem em categorias: (1) potencial regional; (2) nível de integração regional; (3) coesão social; (4) modos de governança de transferência de tecnologia e (5) barreiras regionais.

No primeiro tipo, que corresponde ao potencial regional, as regiões foram agrupadas em três categorias de acordo com a infraestrutura e capacidades institucionais bem como com as políticas e organização das empresas, das quais derivam os SRIs: (1) 
regiões com forte capacidade para desenvolvimento regional e sistema de inovação; (2) regiões com médio potencial para SRI e (3) regiões com baixa capacidade para SRI.

No segundo tipo, sobre o nível de integração regional agrupam-se duas categorias: (1) "perspectiva top-down”, que corresponde a um pequeno pedaço do SNI ou (2) “perspectiva bottom-up”, que corresponde a um sistema único com seu próprio conjunto de características internas e interações entre seus diferentes atores.

No terceiro tipo que destaca a coesão social em consonância com as características descritas anteriormente por Ashein; Gertler (2007); Ashein; Coenen (2005). Para estes, na região encontram-se valores derivados de relações sociais que criam e reforçam a confiança dos agentes. Estes valores, por sua vez, são construídos historicamente movidos por hábitos rotineiros, comportamento padrão, sentido de cooperação, entre outros aspectos que dão coesão social, possibilitando assim a construção de condições estruturais para desenvolvimento de processos inovativo.

No quarto tipo, de acordo com os modos de governança e transferência de tecnologia os SRIs podem ser: (1) “grassroots”, cuja governança e transferência de tecnologia é principalmente realizada em nível local; (2) em rede, que resulta num multinível de governança e transferência de tecnologia, seja local, regional, nacional ou global; (3) “dirigiste”, onde a região é definida como produto de políticas governamentais centrais.

Nesta perspectiva, o quinto e último tipo aponta as barreiras regionais e obstáculos à inovação categorizando da seguinte forma: (1) SRI superficial, cuja região apresenta falta de atores relevantes para permitir o aprendizado coletivo; (2) SRI fragmentado, cuja região mostra uma falta de cooperação e confiança mútua entre os atores e (3) SRI fechado, cuja região é caracterizada por indústrias de tecnologias obsoletas (DOLOROUX, 2002).

Em outro esforço de classificação, Cooke; Uranga; Etxebarria (1998) registram que regiões, cuja dinâmica inovativa é reconhecida como uma das principais características, são as que evoluem em direção a um SRI forte. Enquanto, outras por apresentarem características que não contribuem para desenvolvimento inovativo firmase como SRI fraco. Elegem, para tanto, requerimentos que as classificam como portadoras de SRIs fortes e fracos. Dentre os principais elementos considerados fortes figuram: $1^{\circ}$.) cultura cooperativa; $2^{\circ}$.) desejo de associativismo; $3^{\circ}$.) disposição de aprendizagem; $4^{\circ}$.) consenso público-privado; $5^{\circ}$.) relações de trabalho confiáveis; $6^{\circ}$.) cooperação no local de trabalho; $7^{\circ}$.) busca por inovação; $8^{\circ}$.) delegação de funções, entre outros; Enquanto, 
os elementos pautados como fracos expressam em: $1^{\circ}$.) cultura competitiva; $2^{\circ}$.) individualismo; $3^{\circ}$.) indisposição para aprendizagem; $4^{\circ}$.) dissensão público-privado; $5^{\circ}$.) relações de trabalho antagônicas; $6^{\circ}$.) dispersa divisão de trabalho; $7^{\circ}$.) dificuldade de adaptação; $8^{\circ}$.) centralização de funções, entre outros.

3. Sistema Regional de Inovação: construção histórica para interação, aprendizagem e relacionamentos sistêmicos

A construção de um sistema regional de inovação depende do passado histórico da região, marcado pela presença de especialização produtiva, da dotação de infraestrutura e configurações institucionais. Em verdade, regiões criam path dependences, demonstrando que a história importa na construção do desenvolvimento, dado que o passado possibilita no presente, construir a estrutura desejada no futuro. Neste sentido, regiões podem alterar suas trajetórias de desenvolvimento. Como observa Wolf (s/d, p. 11) “(...) não faltam exemplos de localidades e regiões que alteraram sua trajetória de desenvolvimento através de esforços coletivos para melhorar a sua dotação de seus fatores produtivos e institucionais”. Assim como regiões podem avançar, podem, também, regredirem em seus processos de desenvolvimento. Regiões podem deparar com dependência do caminho que conduz a lock-ins políticos, estruturais e cognitivos, que se tornam obstáculos a constituição de trajetórias de desenvolvimento dentro de um novo paradigma tecnológico.

No propósito de apontar características virtuosas nos sistemas regionais de inovação, Cooke et all (1998) consideram, no nível institucional, a existência de cultura cooperativa, associativismo, disposição de aprendizagem, orientação para mudança, consenso público-privado. Enquanto no nível empresarial, encontram-se presentes as relações de trabalho de confiança, cooperação no local de trabalho, orientação para o bemestar do pessoal, liderança inspiradora, externalização positiva e desejo de inovação. E, no tocante ao nível da organizacional, desenvolvem políticas voltas à inclusão, monitoramento e delegação de ações, prestação de consultoria e atuação em rede. Tais características virtuosas permitem, como afirma Jumer (s/d, p. 10), que (...) regiões da Lombardia na Itália; Baden-Württemberg, na Alemanha; Rhone-Alpes, na França; e, Cambridge no Reino Unido e outras”, sejam exemplos virtuosos.

Nestes termos, a região constitui espaço de organização econômica cujas interações entre atores e criam-se condições para o desenvolvimento de políticas e 
medidas voltadas a aumentar a capacidade de inovação. Afinal, em determinado espaço territorial, empresas, institutos de pesquisa, universidades, agências de promoção à transferência de tecnologia, instituições financeiras e outros órgãos governamentais de apoio desenvolvem relações interativas que se expressam em troca de informações, criação de conhecimento, acordos de cooperação, parcerias inovativas, divisão de funções, infraestrutura pró-inovação, etc.

Contudo, existem diferentes formas de interação, Jump (s/d) em seu estudo classifica em dois blocos para análise, a saber: 1. interação da diretamente relacionado com as atividades de P\&D nas empresas, que se expressa em: a) interação entre empresas - atividades conjuntas de investigação e desenvolvimento de várias empresas, por vezes levadas a cabo através de intermediários; b) interação entre empresas e organizações públicas em P\&D como universidades, institutos de pesquisa, direta ou mediada; 2. interação indireta entre empresas e outros atores, contida em : a) disseminação de tecnologias baseadas em relações de mercado (aquisições de tecnologia, licenças, patentes); b) transferência de tecnologia, devido à mobilidade dos trabalhadores.

Para Cooke et all (1998), é numa determinada região que existe uma 'estrutura de produção' composta de empresas produtoras e fornecedoras voltadas à fabricação especializada de produto, e uma 'estrutura institucional' de apoio que cria condições para a desenvolvimento de processos inovativos. A partir destas estruturas, as interações e inter-relações entre empresas e demais atores geram fluxos de conhecimento e promovem processos de aprendizagem localizados, vitais para a ocorrência de inovações. Nesta linha, observam Doloreux; Parto (2005, apud: Barquero, 2001), que a região age como arena, onde os agentes locais interagem e trocam bens, serviços, experiências e outros ativos tangíveis e não tangíveis que resultam em mudanças técnicas importantes, para a construção de condições competitivas dos agentes econômicos regionais.

Considera-se que o agrupamento de empresas facilita a criação, difusão e transferência do conhecimento. Segundo Wolf (s/d) a proximidade espacial entre os agentes permite a troca de conhecimento dada a existência de economia de tempo e distância. Assim como, a compreensão e transferência do conhecimento são facilitadas pelo fato dos agentes participarem do mesmo ambiente econômico. Por estarem situados na mesma área geográfica, compartilham um conjunto comum de valores e cultura que permite a interação face-a-face facilitando, assim, a ocorrência de troca de conhecimentos que aceleram processos de aprendizagem. 
Assim sendo, tais condições permitem que os agentes respondam, de forma rápida, às mudanças que estão ocorrendo no setor econômico que participam, compreendendo e absorvendo as novas formas de conhecimento. O processo concorrencial tem evidenciado cada vez mais, a necessidade de respostas rápidas ás mudanças que ocorrem no ambiente econômico. E, nem sempre as capacitações estão enraizadas no local, há necessidade de buscar novos conhecimentos externos para serem transformados internamente e gerarem inovações sustentadoras de melhores condições competitivas. Logo, a competência existente no local permite incursões em outros espaços regionais e tirar melhor proveito das condições existentes (TEECE, PISANO, 1994; TEECE, PISANO, SHUEN, 1997 e 2014; COHEN, LEVINTHAL, 1990; ZARA, GEORGE, 2002).

Em destaque, para ocorrência de processos de aprendizagem e aumento do estoque de conhecimento como condição importante para o desenvolvimento inovativo, uma região deve contar com instituições de ensino em seus diferentes níveis. E, em particular, contar com estruturas que a partir de ensinos técnico e superior com propósitos de qualificarem os trabalhadores. Assim como, ter a presença de universidades e institutos de pesquisa cujas atividades de ensino, pesquisa e extensão estejam voltadas às áreas de conhecimento que promovam o desenvolvimento do progresso técnico. Existem áreas do conhecimento que são portadoras do progresso técnico - eletrônica, química, materiais, biotecnologia - que impulsionam o processo inovativo não só no setor específico, mas em vários setores econômicos vinculados, dado sua capacidade de impulso, gerando inovações de primeira e segunda grandezas.

A proximidade dos atores numa determinada região cria condições de transbordamento do conhecimento e difusão do conhecimento tácito. Requer, para tanto, desenvolver condições para tal ocorrência, e dentre destas encontra-se o capital social. Assim sendo, valores como de solidariedade, engajamento cívico, reciprocidade e confiabilidade entre os atores são considerados importantes para a ocorrência de ação conjunta em muitas dimensões, dentre as quais as voltadas à promoção da inovação. Como observam Cooke, et all (1998) tais características reinantes contribuem para a formação de identidade coletiva ou em outros termos, a constituição de ação coletiva, como apontou Commons (2003), que auxiliam nas posturas cotidianas dos atores e no estabelecimento de estratégias regionais de maior alcance.

A densidade e a qualidade das infraestruturas para a inovação são elementos importantes a serem considerados numa região para que as são relevantes uma vez que as relações sistêmicas constituam densas. Como observam Cooke et all (1997) existem 
regiões que dependem fortemente da administração central e não tem controle sobre o tipo de infraestruturas construídas, enquanto outras são mais independentes e possuem maior controle e autonomia para desenvolvimento infraestrutural. Em destaque apontam tipos de condições infraestrututais que possibiltam uma região construir seu sistema de inovação.

Em relato, Cooke et all (1997) citam-se os principais elementos que devem ser considerados : (1) capacidade autónoma para a despesa pública regional; (2) capacidade regional de impor impostos; (3) necessidade de as empresas se aproximar do mercado de capitais nacionais; (4) nível de interrmediários financeiros regionais; (5) controle do governo regional sobre intermediários financeiros; (6) desenvolvimento de políticas de informação e promoção regionais: (7) controle regional sobre a execução de parte das infraestruturas estratégicas; (8) controle ou execução compartilhada (estado / região) de infraestruturas estratégicas; (9) densidade e qualidade de infraestruturas para a inovação estão espalhados e/ou concentradas no espaço regional; (10) sistema de ensino e formação profissional; 11) universidades e institutos de pesquisa especializados; (12) controle sobre os intermediários financeiros; e, (13) políticas de Estado para a indústria, ciência e tecnologia.

Além destas, outras instituições vitais se encontram presentes num sistema regional de inovação. Cita-se, a importância de se região contar com as instituições financeiras - bancos locais e bancos regionais -, disponibilizando recursos para as demandas específicas. Da mesma forma, a região contar com instituições governamentais que elaboram orçamentos e realizam investimentos infraestruturais - transporte, energia e comunicação - em proveito do desenvolvimento regional. Assim como, ter presente instituições representativas de empresários e de trabalhadores, tais como sindicatos e associações de classe, congregando e defendendo os interesses de seus representantes, entre outras. Enfim, como observam Doloreux e Parto (2005, p. 8) uma região deve contar com “(...) instituições que operam em e através de diferentes arenas, que podem ser agrupados em níveis de inter-relação (indivíduos, organizações e sociedade), escalas de governança (local, regional e nacional) e sistemas diversos (econômico, social e político).

Em complemento, um sistema inovativo estabelecido em uma região geográfica deve, também, considerar instituições extra-regionais que geram e circulam o conhecimento. Estas, podem auxiliar às condições de desenvolvimento inovativo que se encontram estabelecidas no espaço regional. Em outros termos, um SRI ativo requer o 
desenvolvimento de ações além do seu espaço geográfico de atuação. E respaldo a esta observação, Ashein; Gertler (2007) sugerem que os SRIs devem alargar seus relacionamentos, buscando acesso aos sistemas nacionais de inovação e, sendo possível aos sistemas supra-nacionais de inovação.

Com a globalização das relações econômica em curso, as empresas não se limitam ao mercado nacional e nem ao regional. Estas mantêm filiais e representantes, bem como fornecedores e clientes em diversos espaços regionais e nacionais. Expandem, cotidianamente, suas ações transfronteiras, logo, os sistemas inovatios devem necessariamente considerar várias conexões colaborativas, dentre as quais existentes em outros países. A recomendação de Doloreaux; Parto (2005: p. 144) é sinalizadora: “(...) o que parece marcar as empresas inovadoras de maior sucesso é a capacidade de se conectar com diferentes sistemas de inovação como uma fonte de vantagem competitiva, estar conectado a uma rede mais ampla que oferece uma variedade de fontes de conhecimento $(\ldots)$.

4. À guisa da conclusão: sistema de inovação, espaço para o exercício de política de desenvolvimento.

Como observa o documento da OCDE (1999), o conceito de sistema de inovação, fornece um instrumental para analisar as especificidades dos países no processo de inovação e um guia para a formulação de políticas públicas. Seja através do uso do terno nacional ou regional, reforça-se a importância do Estado na definição de estratégias políticas que resultem no estabelecimento de padrões econômicos virtuosos. No cerne destas ações encontram-se o desejo de impulsionar as novas combinações schumpeterianas, postas em termos de novos produtos, processos, matérias-primas, formas de organização e mercado que impulsionam o ambiente econômico (SCHUMPETER, 1982).

Nestes termos, como observa Lundvall, (1992), a existência de atores firmados numa estrutura institucional voltada para o desenvolvimento inovativo possibilita inspirar políticas públicas relacionadas à inovação, tanto para o espaço geográfico nacional como regional. Facilita a ocorrência de tal propósito, o fato do Estado ter conhecimento do contexto institucional em que pode atuar, e consequentemente desenvolver ações voltadas à promoção de mudança técnica. Na linha, Metcalfe, 1995, p. 205) aponta que “O conjunto de instituições, conjuntamente e individualmente, contribuem para o 
desenvolvimento e a difusão de novas tecnologias, e fornece o arcabouço no qual a gestão pública formula e implementa políticas para influenciar o processo de inovação".

A existência de várias estruturas como de conhecimento e pesquisa - universidade e institutos de pesquisa -, financeira - bancos e agências de financiamento -, intermediárias (serviços governamentais, inovação privado), empresas - grandes, médias e pequenas - e de mercado - consumidores -, cria condições para o desenvolvimento de ações públicas. Tais estruturas podem se constituir dimensão-chave, podendo ser objeto de ações de políticas públicas, como: 1) desenvolvimento de arranjos monetáriofinanceiro que viabilizam a criação e o funcionamento de universidades e instituições de pesquisa; 2) política de atração de empresas portadoras do progresso técnico eletroeletrônica, química fina, biotecnologia, nanotecnologia, novos materiais, etc.; 3) estimulo à formação de redes de empresas - troca de informações e conhecimento tecnológicos; 4) construção de mecanismos de interação entre atores participantes (problemas, desafios, projetos, parcerias); e, 5) desenvolvimento cultura de cooperação a partir de ações pública-privada - protocolos de intenção, reuniões sistemáticas, entre outras.

Nestes termos, o Estado deve ter condições de desenvolver ações voltadas à construção de estrutura favorável ao desenvolvimento de processo inovativo, considerado fator-chave para o desenvolvimento. Seja em nível nacional ou regional, a responsabilidade estatal deve ser interativa com o setor privado, em regime de parceria no firmamento de estratégia de responsabilidade conjunta e coalização de interesses comum, entre as partes. Em apoio tal procedimento, Cooke (2001) sugere que devem ser construídos sistema de indicadores de inovação, fazer avaliações periódicas, estabelecer objetivos e metas e traçar perspectivas de desenvolvimento de longo prazo

\section{REFERÊNCIAS BIBLIOGRÁFICAS}

ASHEIN, B. T.; COENEN, L. Knowledge bases and regional innovation systems: Comparing Nordic clusters. Research Policy, v.34, p.1173-1190, 2005.

ASHEIN, B. T.; GERTLER, M. S. The geography of innovation: Regional Innovation Systems . In: FAGERBERG, J.; MOWERY, D. C.; NELSON, R.R. The Oxford Handbook of Innovation. New York: Oxford University Press, p.291-317, 2007.

COHEN, W.; LEVINTHAL, D. Absorptive capacity: a new perspective on learning and innovation. Administrative Science Quartely, vol. 35, n. 1, Special issue: Technology, Organizations and Innovation. Mar.1990, pp. 128-152. 
COMMON, J. R. Economia institucional. Revista de Economia Institucional vol.5, no. 8, p. 191-201, 1o. sem. 2003.

COOKE, P.; URANGA, M. G.; ETXEBARRIA, G. Regional innovation systems: Institutional and organisational dimensions. Research Policy, v.26, p.475-491, 1997.

COOKE, P.; URANGA, M. G.; ETXEBARRIA, G. Regional systems of innovation: an evolutionary perspective. Environment and Planning A, v.30, p.1563-1584, 1998.

COOKE. P. Strategies for regional innovation systems: learning transfer and applications. Centre for Advanced Studies Cardiff University, Texts for Discussion, 2001, 25p.

COOKE, P. Regional innovation systems, clusters and the knowledge economy. Center for Advanced Studies, Cardiff University, Texts for Discussion, 2002, 27 p.

DOLOREUX, D. What we should know about regional systems of innovation. Technology in Society, v. 24, p.243-263, 2002.

DOLOREUX, D; PARTO, S. Regional innovation systems: Current discourse and unresolved issues. Technology in Society, v. 27, p.133-153, 2005.

DOSI, G. Sources, Procedures and Microeconomic Effects of Innovation. Journal of Economic Literature, vol. XXVI, n. 3, p. 1120-1171, September 1988.

EDQUIST, C. Systems of innovation: technologies, institutions and organizations. London: Pinter, 1997.

EDQUIST, C. Systems of Innovation: perspectives and challenges. In: FAGERBERG, J.; MOWERY, D. C.; NELSON, R.R. The Oxford Handbook of Innovation. New York: Oxford University Press, p.181-208, 2007.

ELAN, M. National imaginations and systems of innovation. In: EDQUIST, C. Systems of innovation: technologies, institutions and organizations. London: Pinter, p.157-173, 1997.

FAGERBERG, J.; SAPPRASERT, K. National innovation systems: the emergence of a new approach. Science and Public Policy, v. 38, p. 669-679, 2011.

FREEMAN, C. Technology Policy and Economic Performance: lessons from Japan. London/New York: Pinter Publishers. 1987.

FREEMAN, C. The national system of innovation in historical perspective. Cambridge Journal of Economics, v. 19, p.5-24, 1995.

FREEMAN, C.; SOETE, L. A Economia da inovação industrial. Campinas: Ed. da Unicamp, 2008.

HUMPHREY, J.; SCHIMITZ, H. Governance and upgrading: linking industrial cluster and global value chain research. IDS Working Paper, No.120, Institute of Development Studies, Brighton: University of Sussex, 2000.

JUMP, Karel. Systems of Innnovation and regional development. Stanford University. Texts for Discussion, (s/d) $15 \mathrm{p}$.

LIST, F. The national system of potical economy. Longmans, Green and Co., London, 1841.

LUNDVALL, B. National systems of innovation: towards a theory of innovation and interactive learning. London: Pinter Publishers, 1992. 
LUNDVALL, B. National Innovation Systems: Analytical Concept and Development Tool. Industry and Innovation, v. 14, n.1, p. 95-119, 2007.

LUNDVALL, B.; JOHNSON, B.; ANDERSEN, E. S.; DALUM, B. National systems of production, innovation and competence building. Research Policy, v.31, p.213-231, 2002.

LUNDVALL, B.; JOSEPH, K. G.; CHAMINADE, C.; VANG, J. Handbook of innovation systems and developing countries. London: Elgar Publishing, 2009.

METCALFE, J. S. The economic foundations of technology policy: equilibrium and evolutionary perspectives. In: STONEMAN, P. Handbook of Economics of Innovation and Technological Change. Blackwell, Oxford, 1995, p.409-512.

NELSON, R. R. National Innovation Systems: a comparative analysis. New York, Oxford: Oxford University, 1993.

NELSON, R. R.; ROSENBER, N. Technical innovation and national systems. In: NELSON, R. R. National innovation systems: a comparative analysis. Oxford University Press, Oxford (1993): 1-18.

NIOSI, J. National systems of innovations are "x-efficient" (and x-effective). Why some are slow learners. Research Policy, v.31, p.291-302, 2002.

NIOSI, J.; BELLON, B.; SAVIOTTI, P.; CROW, M. Les systèmes nationaux d'innovation : à la recherche d'un concept utilisable. Revue française d'économie, v. 7. , n.1, p. 215-250, 1992.

OCDE - ORGANISATION DE COOPÉRATION ET DE DÉVELOPPEMENT ÉCONOMIQUES . Gérer les systèmes nacionaux d’innovation. Paris: OCDE, 1999.

PIETROBELLI, C.; RABELOTTI, R. The global dimension of innovation systems: linking innovation systems and global value chains. In: Lundvall, B. A. et al. (eds.) Handbook on innovation system and developing countries. Edward Elgar. 2009.

PIETROBELLI, C.; RABELOTTI, R.. Global value chains meet innovation systems: are there learning opportunities for developing countries? World Development, 39(7), 1261-1269, 2011.

SCHUMPETER, J. Teoria do desenvolvimento econômico. Abril Cultural: SP, Série Os Economistas, 1982.

TEECE, D. J.; PISANO, G, The dynamic capabilities of firms: an introduction. Industrial and Corporate Change, 3(3), 1994, pp.537-556.

TEECE, D.; PISANO, G.; SHUEN, A. Dynamic capabilities and strategic management. Strategic Management Journal, 18(7), 1997, pp. 509-533.

TEECE, D.; PISANO, G.; SHUEN, A A dynamics capabilities-based entrepreneurial theory of the multinational enterprise. Journal of International Business Studies, 45, 2014. p. 8-37.

WOLF, D. A. Globalization, information and communication technologies and local and regional systems of innovation. Department of Political Science. University of Toronto, Texts for Discussion, s/d, $20 \mathrm{p}$. 